\title{
ESTIMATION OF ELECTRONIC PROGRAMME GUIDE USE BEHAVIOUR BASED ON THE SWITCHING COST EVALUATION
}

\author{
Domagoj FRANK, Ivan BUDIMIR, Marin MILKOVIĆ
}

\begin{abstract}
In this article we define a new technology acceptance research model which considers the comparison of two technology solutions that an individual can use. The model estimates the usage of the observed solution based on the cost of switching from the reference solution (typically a standard or older solution) to the observed solution, considering the fact that the cost of switching is caused by a difference of facilitating conditions, habit and the intention to use between the reference and observed solutions. For evaluation purposes, we observed the costs of switching from teletext use to the use of the electronic programme guide (EPG on the subset of $n=82$ respondents and interpreted $77.2 \%$ of the variance, which demonstrates the high quality of the model. Evaluation results indicate that the primary obstacle to switching from teletext to EPG usage arises from the individuals' perception whether they have more or less of the necessary resources to use the EPG in comparison to the resources they have at their disposition in case of teletext use, and the second ranked switching cost is caused by a difference in habit.
\end{abstract}

Keywords: electronic programme guide; lazy user theory; switching costs; technology acceptance; teletext; UTAUT2

\section{INTRODUCTION}

Digitalisation of the distribution of television made the electronic programme guide (EPG) omnipresent on each television set, regardless of the distribution network type terrestrial, satellite, cable, IPTV or the Internet. Almost every viewer has access to an EPG that provides "continuously updated information displaying scheduling information for current and upcoming programming" [1]. Research by Ericsson [2] and Nielsen [3] show that the consumption patterns of television and audio-video content are rapidly changing: consumers watch television more and more in a non-linear manner - at a time which suits them, on computers, tablets and smartphones, which allow them to watch television anywhere. Moreover, the amount of content available to the consumer is growing, which creates a problem of searching through the content and selecting it. To serve such needs, EPG application is commonly used for time-shift and content search features. Historically, the programme schedule was available in the printed form [4], either in the form of a programme schedule in the daily newspapers or in the form of a specialized magazine with a weekly programme schedule, then as information presented by teletext systems [5], and in more recent times on specialized Internet portals and mobile applications.

The study that evaluated the use of the EPG based on the Unified Theory of Acceptance and Use of Technology 2 (UTAUT2) model [6] revealed, among other findings, that only 130 out of 234 respondents primarily select the EPG as an information source, although it is readily available on every television set, and that the total of 82 respondents still use teletext as a source of information for displaying the scheduling information. While the use of the UTAUT2 based model proved to be adequate for determining the motivators for using the EPG and explained $78 \%$ of the variance, explaining the reasons why respondents still use the legacy solution (i.e. teletext) is not possible by using the UTAUT2 model because it allows research only on a single solution or technology, disregarding the existence of all other solutions for the same individual's requirement or need. In order to consider multiple solutions to the individual's requirement, an approach similar to the Lazy User Theory would be needed $[7,8]$.

In this article we define a new research model which considers the comparison of two solutions that an individual can select and use. The model estimates the usage of the observed solution based on the cost of switching from the reference solution (typically a standard or older solution) to the observed solution, which would typically be based on the newer technology. For the evaluation of the model, we observe the costs of switching from teletext use to the use of EPG based on the same data set that is used in the UTAUT2 based study [6] to enable comparison of research models.

\section{LAZY USER THEORY}

The Lazy User Theory (LUT) tries to define a framework that would allow the studying of the behaviour of an individual (the User), taking into account his needs on the one hand and his current state on the other hand in order to choose a solution from the set of all possible solutions based on the least effort principle [7,8]. LUT's focus is on the characteristics and needs of the user, which LUT sees as the most important factors in technology acceptance. According to LUT, the user selects a solution to meet his needs from the subset of universal (all possible) solutions, which is limited by the user's state, i.e. the current capabilities and/or circumstances surrounding the user, namely a set of solutions that are available to him and are a subset of a universal set of solutions (Fig. 1).

When choosing a solution, the user valorises the effort he or she assumes will be needed when choosing one of the solutions and selects the one that requires the least effort. Namely, LUT suggests that the user automatically applies the path of least resistance and automatically selects the solution that requires the least effort. LUT defines user need as "an 
explicitly specifiable want that can be completely fulfilled" [8] for example in the case of an information nature need: the need for the type, depth, quality and completeness of the information and the speed of retrieving that information. User state refers to the conditions in which the user finds himself when he has a need, i.e. needs a particular product, information or service. Those conditions vary depending on the user's location, available devices, time in which the need should be met, and other resources that enable the user to act. Depending on the user's state, a subset of solutions from the universal set of solutions is selected and only those that can meet the need in that specific state are retained. Effort is defined in the sense that it involves the necessary time, money and energy to perform a physical or mental task. It assumes that less is necessary and better, that is, that the user inevitably chooses a solution that requires less money, time or energy spent.

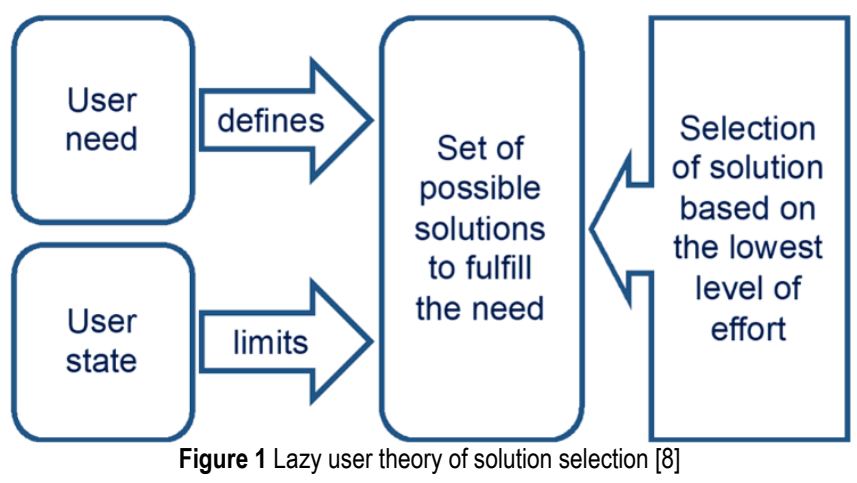

The Lazy User Theory introduces switching costs - the cost that a user estimates is generated when one has to decide whether to switch from using one solution to meet his needs to another solution. The theory uses the concepts that in 2002 Thompson and Cats-Baril [9] considered in the Information Technology and Management Theory as the cost associated with the change of suppliers. It also considers the work of Hess and Ricart from 2003 [10] that observes switching costs as an obstacle that prevents the user from switching to a competitor product or service. According to Hess and Ricart, switching costs arise from, in a broader sense, the amount of investment that the user needs to spend in order to use a solution and that includes: software licenses, relationship with the supplier, accumulated knowledge and education, cost of seeking solutions, trust, commitment, and more. Investment may be both a previous and a potential one. When choosing, the customer decides between the previous investments he has already made and potential future investments in which he is yet to invest, i.e. he has to bear a new expense. In order for the user to choose a new solution that requires additional investment, the corresponding return on the new investment must be higher than the benefits that the user enjoys due to the existing investment. Collan and Tetard note that users can also go back to the previously used solution and will, depending on their state and need, choose a solution where the switching costs are minimal. Observing the switching costs helps understand the barriers that prevent users from changing the technology they use for fulfilling their need and from triggering the change in user behaviour. As part of the switching costs, Collan and Tetard particularly emphasize learning and exercise as important factors, and they recognize four phases in the process of accepting the solution:

1. The phase before use, in which users need the information on the solution - way of use, price, ease of use, experience of others, possible disadvantages and other; and on the basis of that information, they build their expectations.

2. First use during which users compare their expectations with the real use, which results in the acceptance or rejection of the system.

3. Early use during which users build their knowledge and experience that lead them toward routine use.

4. Routine use, when users know how to use all the functions they need.

All of the mentioned learning phases are an investment that can be partially transferred (for example, if the new system has a similar interface) or may become a "sunk" cost, i.e. a non-refundable cost in the event of a transition to a new solution without returning to the old ways in the future choice of solutions.

\section{COMPARISON AND THE CHARACTERISTICS OF UTAUT2 AND LUT}

In 2012 Dwivedi et al. [11] categorised a comprehensive set of numerous theories and models used in the technology acceptance research, and in his further work with Williams et al., he concluded in 2015 [12] that the Unified Theory of Acceptance and Use of Technology (UTAUT) developed by Venkatesh et al. in 2003 [13] was widely used and quoted over 5000 times. Venkatesh extended of the original UTAUT model to UTAUT2 [14] by adding three new constructs in order to explain the behaviour of users-consumers. He concluded that UTAUT2 provides significantly better results in explaining the variance of the user's behavioural intention from $56 \%$ (UTAUT) to $74 \%$ (UTAUT2). For use behaviour, i.e. the actual use, UTAUT2 explained $56 \%$ of the variance in comparison to the $40 \%$ of the variance explained by UTAUT on the same set of data. In 2015, Rondan-Cataluna et al. [15] confirmed that UTAUT2, in comparison to other most popular research models, has better performance when research is conducted on end users, i.e. consumers.

UTAUT's purpose is to research the acceptance of information technology in the business environment, where information solutions are often determined by the business policy of the company. UTAUT2 puts focus on the end user, i.e. the consumer, by introducing constructs that value motivational factors related to the perceived cost-benefit, habit or enjoyment of using information technology, but it still holds on to observing only one possible solution, i.e. the use of one information technology, excluding all other possibilities and technologies that the users could select and use to solve their problems or meet their needs. LUT puts users and their needs in the focus and provides a comprehensive framework from the point of observing the 
users' action in solving their need - it assumes that users can choose between all the possible solutions that can fully meet their specific need.

UTAUT2 introduces the construct of Behavioural Intention in the use of technology as an important factor affecting the real use of technology, while LUT includes the cultural and social circumstances that surround the user and contemplates the impact of the available resources on technology acceptance. As the basic variable in user behaviour, LUT observes the generally defined effort in relation to the required time, money and energy needed to perform a physical or mental task, with each user having his own function to transform those factors, and where the degree of effort depends on the user. With that type of definition, it is not possible to establish a repeatable measurement model that corresponds to the needs of the user behaviour measurement. LUT perceives effort in a broader sense as the key decision-making element in the solution selection process, while UTAUT2 precisely specifies seven constructs (Fig. 2) as the decisive factors of Behavioural Intention (BI) as in Eq. (1) that are also included in the "size" of the effort as perceived by LUT.

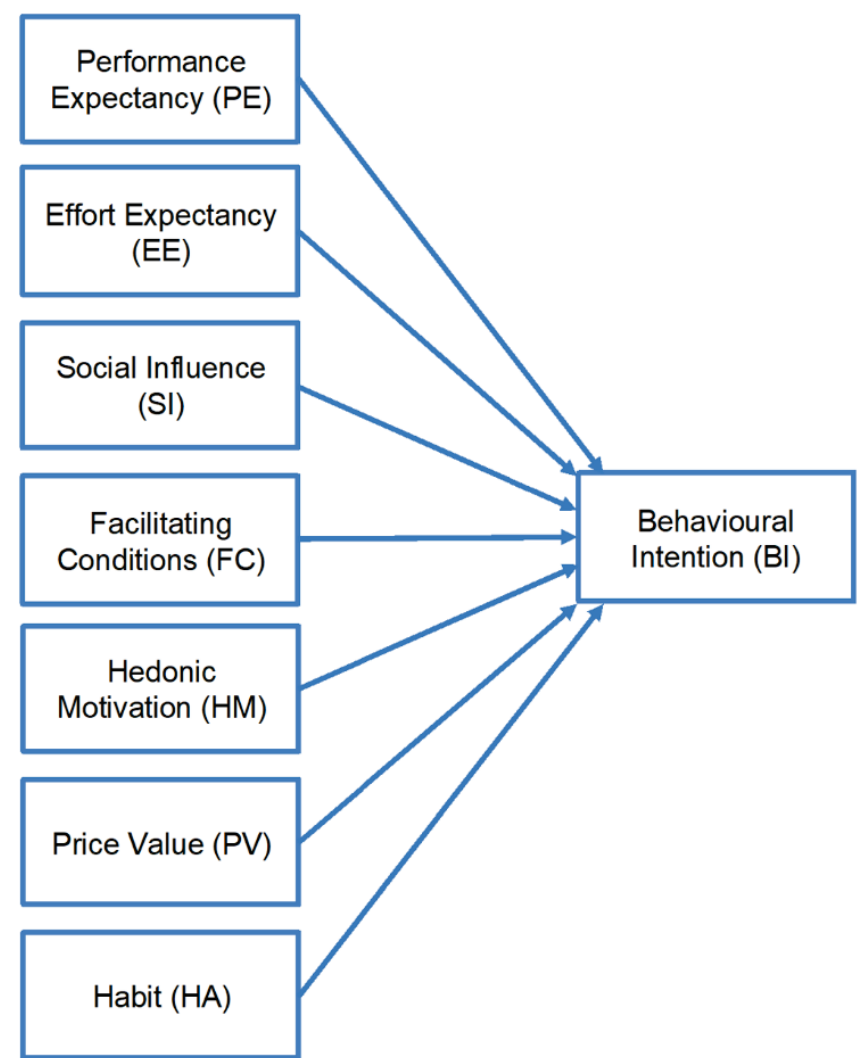

Figure 2 Model of determining Behavioural Intention (BI) according to the UTAUT2 model [14]

- Performance expectancy (PE) determines the user's belief that by using the solution, he will be more efficient and productive.

- Effort expectancy (EE) outlines the user's assessment of the effort needed to become an expert in using the solution.
- Social influence (SI) illustrates the individual's belief that the people surrounding him will support the use of the solution.

- Facilitating conditions $(F C)$ are defined as the "degree to which the individual believes that there is an organizational and technical infrastructure that supports the use of the system". [13]

- Hedonic motivation (HM) determines the individual's expectation or experience that the use of the solution is pleasant or fun.

- Price value $(P V)$ outlines the individual's assessment that the use of the solution will be useful in relation to the monetary compensation (e.g. good value for money).

- Habit (HA) determines the user's assessment of how much, when taking into consideration previous experience, the use of solution will become an everyday routine.

$B I=f(P E, E E, S I, F C, H M, P V, H A)$

In order to measure the user's behaviour, UTAUT2 defines the relation between Use Behaviour (UB) and three other constructs (Fig. 3) as shown in Eq. (2): Facilitating Conditions (FC), Habit (HA) and Behavioural Intention (BI).

$U B=f(F C, H A, B I)$

On a theoretical level, unlike the UTAUT2 model, LUM considers the concepts of effort, switching costs and learning, suggesting a free definition of constructs and relationships among them to the researcher, which makes LUM more of a theory than a research model

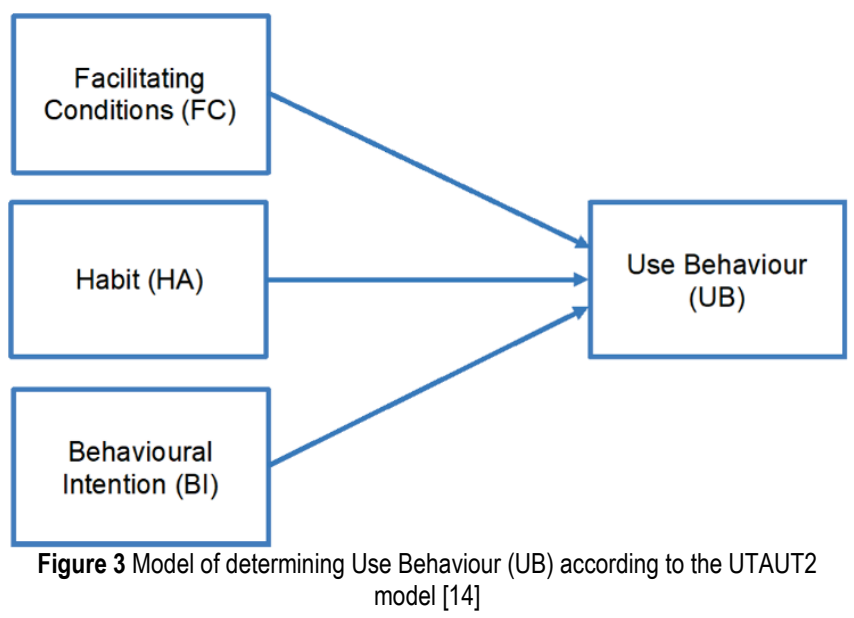

\section{SWITCHING COST RESEARCH MODEL}

In a world where, in order to satisfy their needs, consumers can choose between a number of solutions, the model which could help in the research of consumer behaviour has to put its focus on the user-consumer and his free will to choose the solution that suits him best. At the same time, the model should rigorously determine its constructs in order to define a research framework that allows 
repeatable measurements. The previous chapter shows that none of the existing models alone meet those criteria, but also that UTAUT2 and LUT share features that can be used to create a new model that will meet the required research requirements:

1. The model should enable the comparison of different solutions, i.e. technologies. The goal is to research the behaviour of consumers in the acceptance of the technology that is being observed. Except in the case of completely new services that have not existed so far, the consumer usually already has ways to satisfy his wishes and needs. Therefore, the model must enable the research of effort in the broader sense of the word when consumers switch from the existing behaviour (technology use) to new behaviour, i.e. the use of the technology that is being observed. LUT is a suitable model for the adoption of concepts that meet this requirement.

2. The model must enable the measuring of switching costs that the user must bear in order to switch from the existing solution to the information solution that is being observed in the research. The idea of this concept is elaborated in LUT, but UTAUT2 defines the variables and connections between them that can be adopted to meet this requirement.

3. The model should enable quantitative and repeatable measurements in order to be used to measure the changes in consumer behaviour in time, as well as for various solutions. Therefore, it is necessary to rigorously determine the constructs and relations between them, which is the requirement met by UTAUT2.

Considering the aforementioned requirements, we adopt constructs and relations between them from the UTAUT2 model, hence inheriting a large body of research and knowledge. However, according to the LUT concepts, we observe how the user relates the two possible solutions in terms of the cost of switching from the first (reference) solution to the second (observed) solution - the one that is of research interest. We define three new variables: Facilitating Conditions Switching Costs $\left(S C_{F C}\right)$ as shown in Eq. (3), Habit Switching Costs $\left(S C_{H A}\right)$ as in Eq. (4) and Behavioural Intention Switching Costs $\left(S C_{B I}\right)$ as shown in Eq. (5) that are the differences of the variables Facilitating Conditions, Habit and Behavioural Intention of the reference solution and observed solution.

$S C_{F C}=F C_{R}-F C_{O}$

$F C_{R}-$ Facilitating Conditions, reference solution

$F C_{O}-$ Facilitating Conditions, observed solution

$S C_{H A}=H A_{R}-H A_{O}$

$H A_{R}-$ Habit, reference solution

$H A_{O}-$ Habit, observed solution

$S C_{B I}=B I_{R}-B I_{O}$

$B I_{R}-$ Behavioural Intention, reference solution

$B I_{O}-$ Behavioural Intention, observed solution
The values of Behavioural Intention variables are related to seven variables as defined by the UTAUT2 model (Fig. 2) and are determined separately for the reference as shown in Eq. (6) and observed solution as in Eq. (7).

$$
\begin{aligned}
& B I_{R}=f\left(P E_{R}, E E_{R}, S I_{R}, F C_{R}, H M_{R}, P V_{R}, H A_{R}\right) \\
& B I_{O}=f\left(P E_{O}, E E_{O}, S I_{O}, F C_{O}, H M_{O}, P V_{O}, H A_{O}\right)
\end{aligned}
$$

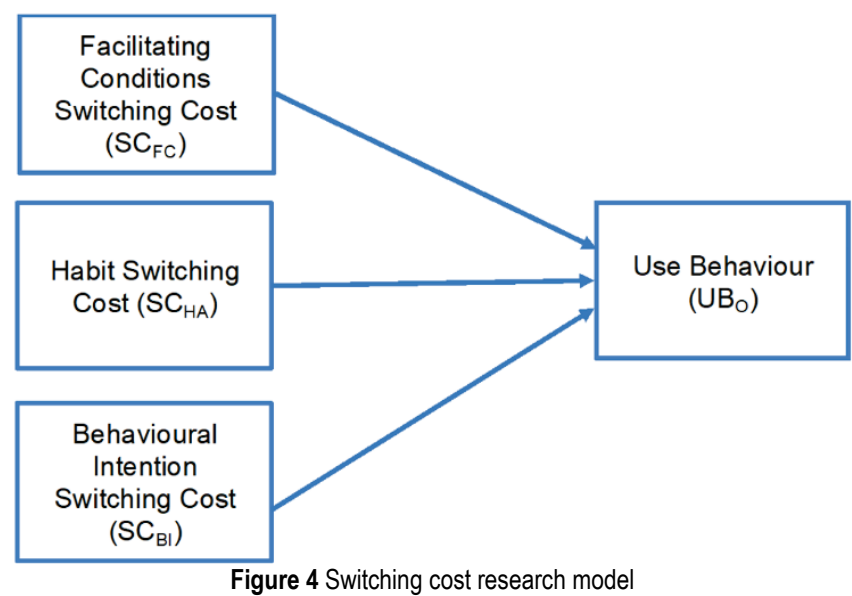

We then observe the influence of the three new variables on the Use Behaviour (UB) (Fig. 4) as in Eq. (8) variable that represents the actual use of the observed solution.

$U B_{O}=f\left(S C_{F C}, S C_{B I}, S C_{H A}\right)$

$U B_{O}$ is the observed User Behaviour.

\section{THE COST OF SWITCHING FROM TELETEXT TO EPG}

For this analysis, the same data set was used as the one in the evaluation of electronic programme guide adoption with UTAUT2 based model [6] in order to enable research result comparison. In the data set, the respondents are users of all solutions that can be used to get information on the television programme schedule, including the electronic programme guide, printed programme guide, teletext and Internet portals and/or applications.

The total number or respondents (Tab. 1) is the largest for the electronic programme guide and equal to the total number of respondents, due to the fact that the survey logic ensured that all respondents provide answers for this solution, as it is the subject of research. The respondents that have selected the electronic programme guide as their first choice, were given the opportunity to select the secondary solution they use ( $2^{\text {nd }}$ choice $) .8$ of them selected a printed programme guide, 28 teletext, 37 Internet portal or application and the rest of 57 respondents asserted that they exclusively use the electronic programme guide. A total of 104 respondents that have selected the printed programme guide, teletext or Internet portal/application as the primary solution $\left(1^{\text {st }}\right.$ choice $)$ were forced to provide responses also for the electronic programme guide.

The teletext is the second most widely used solution with 82 respondents, followed by the Internet portals/applications 
with 73 respondents and finally, by the printed programme guides with only 22 respondents.

Table 1 Solution selection for retrieving TV programme schedule

\begin{tabular}{|l|c|c|c|c|}
\hline Solution used for retrieving & \multicolumn{4}{|c|}{ Number of respondents } \\
\cline { 2 - 5 } $\begin{array}{l}\text { TV programme schedule or } \\
\text { TV show data }\end{array}$ & $\begin{array}{c}1^{\text {st }} \\
\text { choice }\end{array}$ & $\begin{array}{c}2^{\text {nd }} \\
\text { choice }\end{array}$ & $\begin{array}{c}\text { Forced } \\
\text { response }\end{array}$ & Total \\
\hline Electronic programme guide & 130 & - & 104 & 234 \\
\hline Printed programme guide & 14 & 8 & 0 & 22 \\
\hline Teletext & 54 & 28 & 0 & 82 \\
\hline Internet portal or application & 36 & 37 & 0 & 73 \\
\hline
\end{tabular}

The sample of respondents for whom we are observing the cost of switching from teletext usage to the use of the electronic programme guide is $n=82$, i.e. 54 respondents who use teletext as the first choice and 28 primary users of the electronic programme guide, who selected teletext as their second choice (Tab. 1). 54 respondents who selected teletext as the first choice were compelled by the survey logic to answer questions about the electronic programme guide, although some of them possibly never used it.

In the evaluation of the impact of the switching cost concept, we observe the effect of the difference between the constructs defined by UTAUT2: Facilitating Conditions $(F C)$ in case of Teletext usage and the same variable in the case of Electronic programme guide (EPG) usage, Habit (HA), and Behavioural Intention (BI) to the Use Behaviour variable in the case of EPG usage. Therefore, we observe the aggregate switching cost as an effect of the three newly defined variables of Facilitating Conditions Switching Costs $\left(S C_{F C}\right)$ as shown in Eq. (9), Habit Switching Costs $\left(S C_{H A}\right)$ as shown in Eq. (10) and Behavioural Intention Switching Costs $\left(S C_{B I}\right)$ as shown in Eq. (11) to the Use Behaviour $\left(U B_{E P G}\right)$ variable for the case of using the EPG as in Eq. (12).

$S C_{F C}=F C_{T X T}-F C_{E P G}$

$S C_{H A}=H A_{T X T}-H A_{E P G}$

$S C_{B I}=B I_{T X T}-B I_{E P G}$

$U B_{E P G}=f\left(S C_{F C}, S C_{B I}, S C_{H A}\right)$

The $U B_{E P G}$ variable has values from the subset consisting of Teletext users and which contains data collected from $n=82$ respondents. The descriptive statistics (Tab. 2) show that the arithmetic mean obtained on the subset of Teletext users is $\mu=4.646$, which is less than the value of the arithmetic mean of the same variable $(\mu=5.137)$, when observed on the whole sample of $N=234$ respondents in the evaluation of EPG adoption by using the UTAUT2 model [6]. As expected, respondents in the Teletext user subset are on average less likely to use the EPG than the average of the whole set. The median of the $U B_{E P G}$ variable is $M e d=$ 5.500 , which is higher than its arithmetic mean. The same conclusion applies to the mod, which is $\operatorname{Mod}=6.000$, with the frequency of occurrence of $n=23$ respondents of the total of $n=82$ respondents. The variance and standard deviation as data dispersion measures are not large.
Table 2 Descriptive statistics of the Use Behaviour variable

\begin{tabular}{|c|c|c|c|c|c|c|}
\hline Var. & Mean & Median & Mode & $\begin{array}{c}\text { Mod } \\
\text { Freq. }\end{array}$ & Variance & Std. dev. \\
\hline$U B_{E P G}$ & 4.646 & 5.500 & 6.000 & 23 & 4.923 & 2.219 \\
\hline
\end{tabular}

Table 3 Descriptive statistics of the $S C_{F C}, S C_{B I}, S C_{H A}$ variables

\begin{tabular}{|c|c|c|c|c|c|c|}
\hline Var. & Mean & Median & Mode & $\begin{array}{c}\text { Mod } \\
\text { Freq. }\end{array}$ & Variance & Std. dev. \\
\hline$S C_{F C}$ & 1.041 & 0.000 & 0.000 & 35 & 4.687 & 2.165 \\
\hline$S C_{H A}$ & 0.911 & 0.333 & 0.000 & 15 & 6.944 & 2.635 \\
\hline$S C_{B I}$ & 0.967 & 0.000 & 0.000 & 18 & 7.672 & 2.770 \\
\hline
\end{tabular}

The arithmetic means of switching costs from teletext to the electronic programme guide are for the $S C_{F C}, S C_{B I}, S C_{H A}$ variables positive and with an approximate value of $\mu \approx 1$. This shows that, on average, all parameters show a positive cost of switching. However, the medians of all switching cost variables considerably vary from the arithmetic means. Thus, the median $\operatorname{Med}\left(S C_{F C}\right)=0.000, \operatorname{Med}\left(S C_{H A}\right)=0.333$ and $\operatorname{Med}\left(S C_{B I}\right)=0.000$, which is caused by Mode values $\operatorname{Mod}=0$ for all variables. This suggests that for the largest number of respondents, it is all the same whether they use teletext or the electronic programme guide. Variances and standard deviations are of the expected value, which suggests a certain dispersion of data. Therefore, the confidence intervals for the arithmetic mean are of approximate widths of 0.5 units, which implies a relatively high precision of estimating the arithmetic mean of all variables of switching costs (Tab. 4). The minimum and maximum quartiles are quite wide-ranging because the respondents have differently assigned rank variables.

\begin{tabular}{|c|c|c|c|c|c|c|}
\hline Var. & $\begin{array}{c}\text { Confidence } \\
\text { interval } \\
\text { lower limit } \\
-95 \% \\
\end{array}$ & $\begin{array}{c}\text { Confidence } \\
\text { interval } \\
\text { upper limit } \\
+95 \% \\
\end{array}$ & Min & Max. & $\begin{array}{l}\text { Lower } \\
\text { quartile }\end{array}$ & $\begin{array}{l}\text { Upper } \\
\text { quartile }\end{array}$ \\
\hline$S C_{F C}$ & 0.565 & 1.516 & -2.000 & 6.000 & 0.000 & 1.333 \\
\hline$S C_{H A}$ & 0.332 & 1.490 & -6.000 & 6.000 & -0.333 & 2.667 \\
\hline$S C_{B I}$ & 0.359 & 1.576 & -4.333 & 6.000 & -0.667 & 2.667 \\
\hline
\end{tabular}

The correlation analysis of the $S C_{F C}, S C_{B I}, S C_{H A}$ switching costs variables and the, $S C_{H A}$ User Behaviour $U B_{E P G}$ variable was carried out (Tab. 5).

Table 5 Correlation analysis: Pearson correlation coefficient $r$, $p$-value of variables

\begin{tabular}{|c|c|c|c|c|}
\hline Var. & $U B_{E P G}$ & $S C_{F C}$ & $S C_{H A}$ & $S C_{B I}$ \\
\hline \multirow{2}{*}{$U B_{E P G}$} & $r=1.000$ & & & \\
\hline \multirow{2}{*}{$S C_{F C}$} & $r=---$ & & & \\
& $p=0.844$ & $r=1.000$ & & \\
\hline \multirow{2}{*}{$S C_{H A}$} & $r=-0.786$ & $p=0.739$ & $r=1.000$ & \\
& $p=0.000$ & $p=0.000$ & $p=---$ & \\
\hline \multirow{2}{*}{$S C_{B I}$} & $r=-0.795$ & $r=0.816$ & $r=0.852$ & $r=1.000$ \\
& $p=0.000$ & $p=0.000$ & $p=0.000$ & $p=--$ \\
\hline
\end{tabular}

All calculated Pearson correlation coefficients are statistically significant $p<0.05$. A strong negative correlation $(-1<r<-0,8)$ of $r=-0.844$ was determined in the $\left(S C_{F C}, U B_{E P G}\right)$ pair of variables. Moreover, the correlation coefficients $r=-0.786$ and $r=-0.795$, which are on the boundary between the strong and medium 
strong negative correlations $(-0.8<r<-0.5)$, are determined for the $\left(S C_{H A}, U B_{E P G}\right)$ and $\left(S C_{B I}, U B_{E P G}\right)$ variable pair.

A strong positive correlation was found among the $\left(S C_{F C}, S C_{B I}\right)$ and $\left(S C_{H A}, S C_{B I}\right)$ pairs of variables, with the coefficients of correlation $r=0.816$ and $r=0.852$. A medium strong positive link exists between the $\left(S C_{F C}, S C_{H A}\right)$ pair of $r=0.739$. The absolute values of all established correlation coefficients are very high and indicate the existence of strong and medium strong linear relationships between variables (positive and negative).

In order to determine the influence of the switching cost variables from Teletext to EPG, a mathematical model of multiple linear regression was created. Thus, the influence of the dependent switching cost variables of $S C_{F C}, S C_{B I}, S C_{H A}$ on the independent $U B_{E P G}$ variable was examined.

The most important assumption of linear regression is fulfilled because the dependent $U B_{E P G}$ variable has a strong linear correlation with the independent $S C_{F C}, S C_{B I}, S C_{H A}$ variables. However, the dependent $S C_{F C}, S C_{B I}, S C_{H A}$ variables have a very strong correlation with one another, leading to the problem of multicollinearity (Table 6). This fulfils the most important assumptions necessary for the construction of a representative multiple regression model. The model itself includes the determination of the most suitable linear regression function in terms of the optimal minimum squares.

$$
f: \mathbb{R}^{3} \rightarrow \mathbb{R}
$$

The form of the function is as shown in Eq. (13):

$U B_{E P G}=f\left(S C_{F C}, S C_{B I}, S C_{H A}\right)+\varepsilon$

Where $\varepsilon$ is the statistical error of the estimation.

More specifically, the proposed multiple linear regression model of switching costs from teletext to an electronic programme guide is given by a linear equation as in Eq. (14):

$U B_{E P G}=\beta_{0}+\beta_{1} S C_{B I}+\beta_{2} S C_{F C}+\beta_{3} S C_{H A}+\varepsilon$

Where $\varepsilon$ is the statistical error of the estimation.

The multiple linear regression model coefficients are calculated: $\beta$ parameters, standard error of $\beta, t$-statistic values, and associated $p$-values.

Table 6 Correlation analysis: Pearson correlation coefficient $r$, p-value of variables

\begin{tabular}{|c|c|c|c|c|}
\hline Var. & $\beta$ & $\begin{array}{c}\text { Standard error } \\
\text { of } \beta\end{array}$ & $t(78)$ & $p$-value \\
\hline$\beta_{0}$ & 5.532 & 0.133 & 41.672 & 0.000 \\
\hline$\beta_{1}$ & -0.067 & 0.097 & -0.691 & 0.491 \\
\hline$\beta_{2}$ & -0.559 & 0.097 & -5.775 & 0.000 \\
\hline$\beta_{3}$ & -0.262 & 0.088 & -2.988 & 0.004 \\
\hline
\end{tabular}

It was found that the $\beta_{2}$ and $\beta_{3}$ parameters of the model are statistically significant, while the $\beta_{1}$ parameter is not statistically significant $(p<0.05)$. This means that the $S C_{F C}$ and $S C_{H A}$ variables have a statistically significant effect on the $U B_{E P G}$ variable. The $S C_{F C}$ variable influences the $U B_{E P G}$ variable the most. To be more precise, increasing the value of the $S C_{F C}$ variable for one unit causes the $U B_{E P G}$ variable to decrease by 0.559 units. Moreover, increasing the $S C_{H A}$ variable for one unit causes the value of the $U B_{E P G}$ variable to decrease by 0.262 units. The remaining $S C_{B I}$ variable is not statistically significant and does not contribute in a statistically significant manner to the $U B_{E P G}$ variable. Furthermore, its influence is negligible with respect to the beta-coefficient of the $\beta_{1}=-0.067$. The analysis of the standard beta-coefficient errors shows that they are also negligible.

The multiple regression model gives the following linear equation as a solution as shown in Eq. (15).

$$
U B_{E P G}=5.532-0.559 S C_{F C}-0.262 S C_{H A}-0.067 S C_{B I}
$$

Table 7 ANOVA-table of all effects of the linear regression model of variables

\begin{tabular}{|l|c|}
\hline \multicolumn{1}{|c|}{ Statistics } & Values \\
\hline$R$ & 0.879 \\
\hline Coefficient of determination $R^{2}$ & 0.772 \\
\hline Adjusted $R^{2}$ & 0.764 \\
\hline Fisher $F$ & 88.180 \\
\hline$P$ value of the model & 0.000 \\
\hline Standard error of the estimate & 1.079 \\
\hline
\end{tabular}

The coefficient of determination is $R^{2}=0.772$, hence the model explains $77.2 \%$ of the variance. A very high value also belongs to the parameter adjusted $R^{2}=0.764$. The value of Fisher's statistics is $F=88.180$, while the p-value is $P=0.000$. Based on the previously presented data, $\mathrm{p}$ value follows the conclusion that the coefficient of determination $R^{2}$ is statistically significant. The standard error of the estimate is very low and equals 1.079. According to all interpreted indicators, the regression model of the cost of switching from teletext to EPG adequately represents the linear link between the dependent $U B_{E P G}$ variable and the $S C_{F C}, S C_{H A}$ and $S C_{B I}$ predictors.

\section{CONCLUSION}

Our research model defined a concept of switching costs that compares the solutions or technology pairs or competing technologies, and it used for its model evaluation an electronic programme guide as the observed solution and teletext as a reference solution. In the switching cost analysis, we created three new predictor variables: Facilitating Conditions Switching Costs $\left(S C_{F C}\right)$, Habit Switching Costs $\left(S C_{H A}\right)$ and Behavioural Intention Switching Costs $\left(S C_{B I}\right)$, which are the differences of the Facilitating Conditions, Habit and Behavioural Intention variables in the case of using the electronic programme guide and their equivalents for teletext. We then observed the influence of new variables on the Use Behaviour $\left(U B_{E P G}\right)$ variable that represents the use of the electronic programme guide. Arithmetic means of all variables are positive, indicating that on average, there is a positive cost of switching, which suggests that all observed parameters represented by the switching cost variables pose 
an obstacle to a certain degree in the case of switching from using teletext to using the EPG. The correlation analysis further showed that all variables are highly negatively related to the use of an electronic programme guide, which is consistent with the model that says that a higher switching cost reduces the use of the solution. The regression analysis showed that the highest contribution to the cost of switching is mainly caused by the predictor variable of Facilitating Conditions Switching Costs $\left(S C_{F C}\right)$ - increasing $S C_{F C}$ for one unit decreases the EPG usage of $U B_{E P G}$ by 0.559 units. This indicates that the main obstacle to switching from teletext to EPG arises from the individuals' perception whether they have more or less of necessary resources to use the EPG in comparison to the resources they have at their disposition in the case of teletext use. Teletext users will be more reluctant to use the electronic programme guide if they are not sure whether they will get help if they encounter a problem or if they are unfamiliar with the fact that they already have the option of using an electronic programme guide on their TV or digital receiver. Significant influence on the use of EPG is also generated from the difference in the habit of using teletext compared to the habit of using the EPG. An increase of Habit Switching Costs $\left(S C_{H A}\right)$ for one unit decreases the $U B_{E P G}$ by 0.262 units. Teletext users who are faithful to this technology seem to have deeply rooted habits and will need to use the electronic programme guide for some time before it becomes the primary choice when they want to get information on the schedule of television programs. The influence of Behavioural Intention Switching Costs $\left(S C_{B I}\right)$ is not statistically significant, and its impact is negligible, which indicates that the switching cost model could be further simplified in further research.

The coefficient of determination of this model is $R^{2}=$ 0.772 , thus it can interpret $77.2 \%$ of the variance, which demonstrates that the model has a very good representation of the switching cost caused by facilitating conditions, habit and intention to use. It is important to note that this result is achieved on the subsample of only 82 respondents, while the coefficient of determination similar to the one determined in the UTAUT2 based research equals $R^{2}=0.78$, but on a larger sample of 234 respondents.

\section{Acknowledgements}

This research was supported by HP Produkcija d.o.o. which operates "Evotv" - the terrestrial television pay TV service in Croatia.

\section{REFERENCES}

[1] European Telecommunications Standards Institute. (2011). Media Content Distribution (MCD): Programme guide information distribution, situation and perspective (Publication No. ETSI - TR 102 988).

[2] Ericsson Consumerlab. (2017). A consumer-driven future of media - An Ericsson Consumer and Industry Insight Report, Ericsson SE-Stockholm, Sweden.

[3] Nielsen. (2015). Screen wars: The battle for eye space in a TVEverywhere world, The Nielsen Company.
[4] Dawes, C. (2015). From Paper to Digital Glory: The Progression of the Entertainment Guide, CED, 41(5), 30-32.

[5] International Telecommunication Union. (1998). Recommendation ITU-R BT.653-3: Teletext systems, (Publication No. ITU-R BT.653-3)

[6] Frank, D. \& Milković, M. (2018). Evaluation of Electronic Programme Guide Adoption Using UTAUT2 Based Model, Tehnički vjesnik, 25(3), 884-890. https://doi.org/10.17559/TV-20180601095518

[7] Collan, M. \& Tétard, F. (2007). Lazy user theory of solution selection, Proceedings or the CELDA 2007 Conference, Algarve, Portugal, 273-278.

[8] Collan, M. \& Tétard, F. (2009). Lazy User Theory: A Dynamic Model to Understand User Selection of Products and Services, Proceedings of the 42nd Hawaii International Conference on System Sciences, (HICSS-42), Big Island, HI, 1-9.

[9] Thompson, R. L. \& Cats-Baril, W. L. (2002). Information Technology and Management, $2^{\text {nd }}$ ed. New York, NY, USA: McGraw-Hill, Inc.

[10] Hess, M. \& Ricart, J. E. (2003). Managing Customer Switching Costs: A Framework for Competing in the Networked Environment, Mgt Res: J of Iberoamer Ac Mgt, 1(1), 93-110.

[11] Dwivedi, Y. K., Wade, M. R., \& Schneberger, S. L. (Eds.). (2012). Information Systems Theory: Explaining and Predicting Our Digital Society, Vol. 2. New York: SpringerVerlag.

[12] Williams, M. D., Rana, N. P., \& Dwivedi, Y. K. (2015). The unified theory of acceptance and use of technology (UTAUT): a literature review. J. Enterp. Inf. Manag., 28(3), 443-488. https://doi.org/10.1108/JEIM-09-2014-0088

[13] Venkatesh, V., Morris, M. G., Davis, G. B., \& Davis, F. D. (2003). User acceptance of information technology: Toward a unified view, MIS Q. Manag. Inf. Syst., 27(3), 425-478. https://doi.org/10.2307/30036540

[14] Venkatesh, V., Thong, J. Y. L., \& Xu, X. (2012). Consumer acceptance and use of information technology: Extending the unified theory of acceptance and use of technology, MIS $Q$. Manag. Inf. Syst., 36(1), 157-178. https://doi.org/10.2307/41410412

[15] Rondan-Cataluña, F. J., Arenas-Gaitán, J. \& Ramírez-Correa, P. E. (2015). A comparison of the different versions of popular technology acceptance models: A non-linear perspective. Kybernetes, 44(5), 788-805. https://doi.org/10.1108/K-09-2014-0184

\section{Authors' contacts:}

Domagoj FRANK, PhD

University North

Trg dr. Žarka Dolinara 1, 48000 Koprivnica, Croatia

domagoj.frank@unin.hr

Ivan BUDIMIR, Docent, $\mathrm{PhD}$

Faculty of Graphic Arts

Getaldićeva ul. 2, 10000 Zagreb, Croatia

ivan.budimir@grf.hr

Marin MILKOVIĆ, Professor, PhD

University North

Trg dr. Žarka Dolinara 1, 48000 Koprivnica, Croatia

marin.milkovic@unin.hr 